\title{
IT skill requirements in Public Administration
}

\author{
A model of IS Function for Public Administrations in \\ order to identify professional requirements and training \\ needs. The experience of the Department for National \\ General Accounting of the Italian Ministry of Economy \\ and Finance.
}

\begin{abstract}
Pietro Paolo Trimarchi
Ministry of Economy and Finance - Department for National General Accounting (RGS), Italy, pietropaolo.trimarchi@tesoro.it
\end{abstract}

\begin{abstract}
In the last twenty years, the role and the organization of IS function has been undergoing profound changes. Both firms and Public Administrations have not always been able to adapt successfully to new realities. In particular, IS staff often do not have appropriate skills, on the one hand, to translate business needs in IT solutions and, on the other hand, to deal competently with suppliers. The Department for National General Accounting of the Italian Ministry of Economy and Finance is trying to fill these competence gaps through a re-training program for its IS human resources. For this purpose a model of IS function was built. It is the starting point and the goal of the project.
\end{abstract}

Keywords: IS function, public administration, EUCIP

\section{The IS function in today's organizations}

Realizing what the role and the structure of IS function is within modern organizations is the first step to identify IT skill requirements. In fact, not only technical competences, but also business needs have been changing rapidly.

The weight of IT within organizations has been growing. However, the actual change is not the scope of its presence but what it is used for.

Today, automating operational activities represents normality; whereas the new goal of information systems is to support decisions in order to enhance their quality. Therefore, the current purpose of IT is no longer and not only to increase 
processes efficiency but also more and more to improve management effectiveness.

This is true for firms as well as for public administrations. In fact - although they have different aims (firms are subjected to market competition while public administrations are submitted to the consent of the people) - they both need meaningful and well-timed information to achieve, given the resources available, the best results. Therefore, IT requirements of an organization often depend more on its size than on its private or public nature. And, in principle, dealing with the information system (or the IS function) within a public administration or within a firm is substantially the same.

This does not mean there are no differences. Nevertheless, if the level of analysis remains general these differences are not significant. For example, it is known that IT strategy should not only be aligned to business strategy but also should be an active part of it. This concept is valid for firms as well as for public administrations. Of course, suggestions coming from IT will be different in the two different cases, but shouldn't it be the same scenario when speaking about two firms, one having its business in a competitive and the other that has its business in an oligopolistic or a monopolistic market?

The reason is that IT is an instrument as well as IS function is a support function. So their link with the core business of the organization is slack and guidelines about their role and organizational structure can be adapted to different real applications.

As explained, the role of IT within organizations has been changing over time. This is evident when looking at the evolution of enterprise information systems: from transaction processing systems (TPS) to management information systems (MIS), to decision support systems (DSS), to executive support systems (ESS), to supply chain management systems (SCM), to customer relationship management systems (CRM), to knowledge management systems (KMS), etc.

It also follows that the role of IS function has changed, so new skills are required of the people who work in the function. Particularly, there is demand for professionals who are able to translate business needs in IT solutions and to suggest IT opportunities to improve business.

But another important change has occurred in IS function: it is IT outsourcing. In fact, complexity of new technologies, on the one hand, and necessity to concentrate on core business and to reduce expenses, on the other hand, have pushed many organizations to entrust specialized firms with most of information systems management.

In this case there are not significant differences between public and private organizations (except for the rules of outsourcers selection) too.

Even though it is not the aim of these pages to examine pros and cons of outsourcing, many authors have underlined that it can bring about losing control over IT strategy. Moreover, the consequent reduction of internal competences can cause IT suppliers to take advantage of clients. 
Finally, there are three items useful in identifying IT skill requirements for modern organizations: state of technology, role of IT and form of sourcing. Furthermore, experience of firms is also applicable to public administrations.

\section{Organizing the IS function}

The state of technology and the role of IS function within the organization determine IT skill requirements, and the form of sourcing determines which skills internal staff must possess and which skills IT suppliers must possess.

Moreover, the form of sourcing should be chosen according to the role of IS function within the organization and the state of technology. For this reason, an appropriate structure of the function can be determined only by reconciling these three items.

\subsection{Tasks and processes of the IS function}

Various models of IS function management can be found in specialized literature. Usually, they effectively describe processes that must take place in order to assure correct functioning of information systems and suitable support to business. These processes sometimes are placed in a life cycle based framework, other times are classified according to the value chain method.

On the contrary, contributions about tasks assigned to the different units of the IS function are more generic.

Of course, that is for internal structure of the function depends from peculiar needs of each organization; furthermore IT processes pass through the whole IS function, so it is very difficult to synthesize such a complexity in a sort of organization chart. Nevertheless, determining who does what within the IS function could help to give some guidelines for organizing it and, afterwards, for identifying skill requirements.

To these aims it could be useful to build a model of IS function based on a functional point of view, composed by sets of homogeneous activities, that according to the characteristics of each organization - can represent organizational units, persons or, more simply, critical tasks ensuring success of IT processes.

Generically, each of those sets could be viewed as the owner of distinct processes described in other models based on processes. 


\subsection{A model of IS function ${ }^{1}$}

The model proposed in these pages has been built beginning from well-known models based on processes (like COBIT, ITIL and others), by disassembling these processes in activities and by assembling these activities in homogeneous areas.

As well as every model, this is a simplification of realty, in fact - depending on the effective needs of each organization - every set of activities can be further split or, alternatively, can be joint with other sets. However, being based on appreciated models based on processes, this model probably maps all the activities that are performed in the IS function. Moreover, its structure points out functional connections among the distinct units without referring to hierarchic relations, so that it is abstract enough to be adaptable to different actual cases.

\subsubsection{The general model}

The general model, that includes all activities without considering the event of outsourcing, is represented in Figure 1.

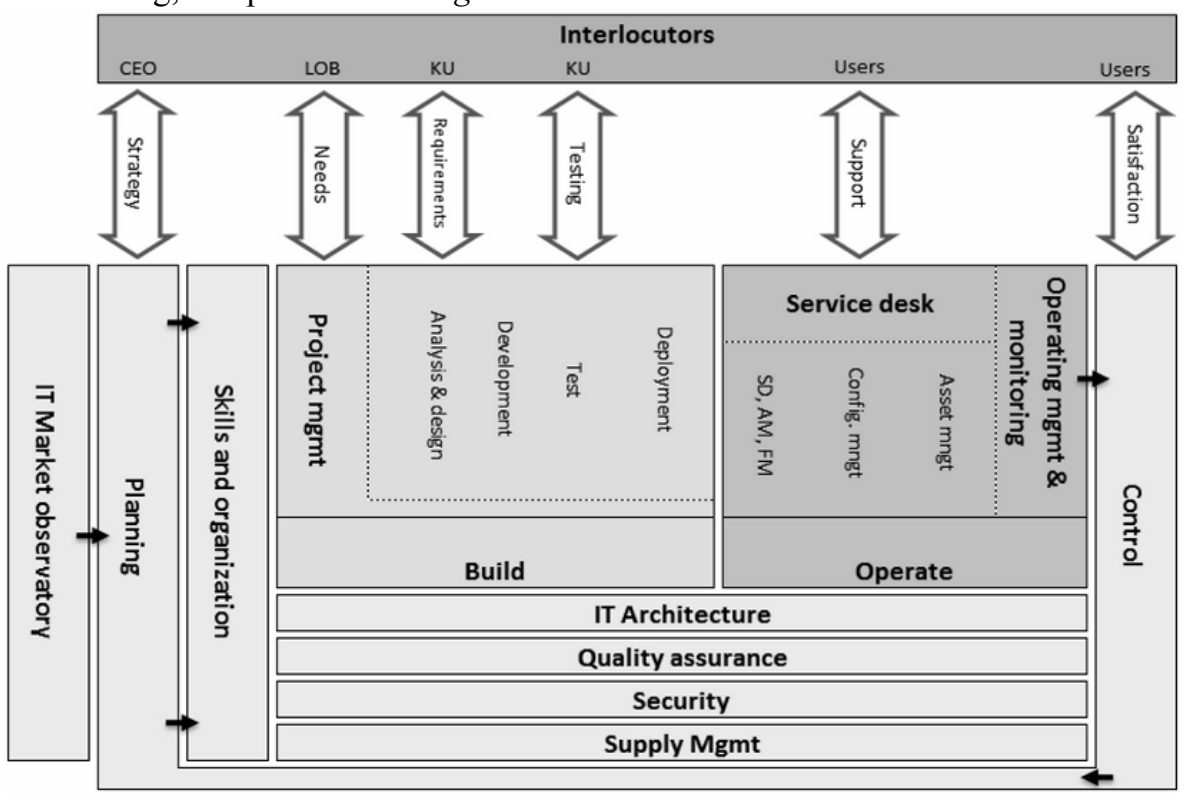

Figure 1 A model of the IS function.

${ }^{1}$ A detailed description of the model is not the aim of this document, so it will be only outlined. It is the result of a work performed by the IS staff of the Italian Ministry of Economy and Finance (MEF) - Department for National General Accounting (RGS) as a contribution to a project for IT professionals reviewing, still in progress, run by the IT National Centre for PA (CNIPA). 
In a few words, each module of the model - that represents an homogeneous activities area - could be viewed like an IS sub-function that is the process owner of one or more processes. For example, the IT annual planning is a process shared by many units within IS function, but it is coordinated by the sub-function "Planning and control", that is its process owner.

Within the model it is possible to distinguish three macro-areas: Build and Operate, respectively, include systems development and service delivery and support; the third, that could be called Governance, includes activities assuring the consistency of the whole information system.

\subsubsection{The model with outsourcing}

As said, owing to complexity of new technologies and exigency to cut costs, most of the organizations outsource information systems management.

Even though typology and intensity of IT outsourcing are very different, in principle, it is wise at least to keep inside a skilled staff able to decide and govern the IT strategy. But the strength of this advice, after all, depends on how much strategic IT is considered by each organization.

With regard to outsourcing, one property of the model under discussion is that, being modular, it is adaptable to every concrete situation.

In Figure 2 is represented a typical case of IT outsourcing, where technical activities are delegate to outsourcers while strategy, leadership and service level management are due of the "internal" IS function.

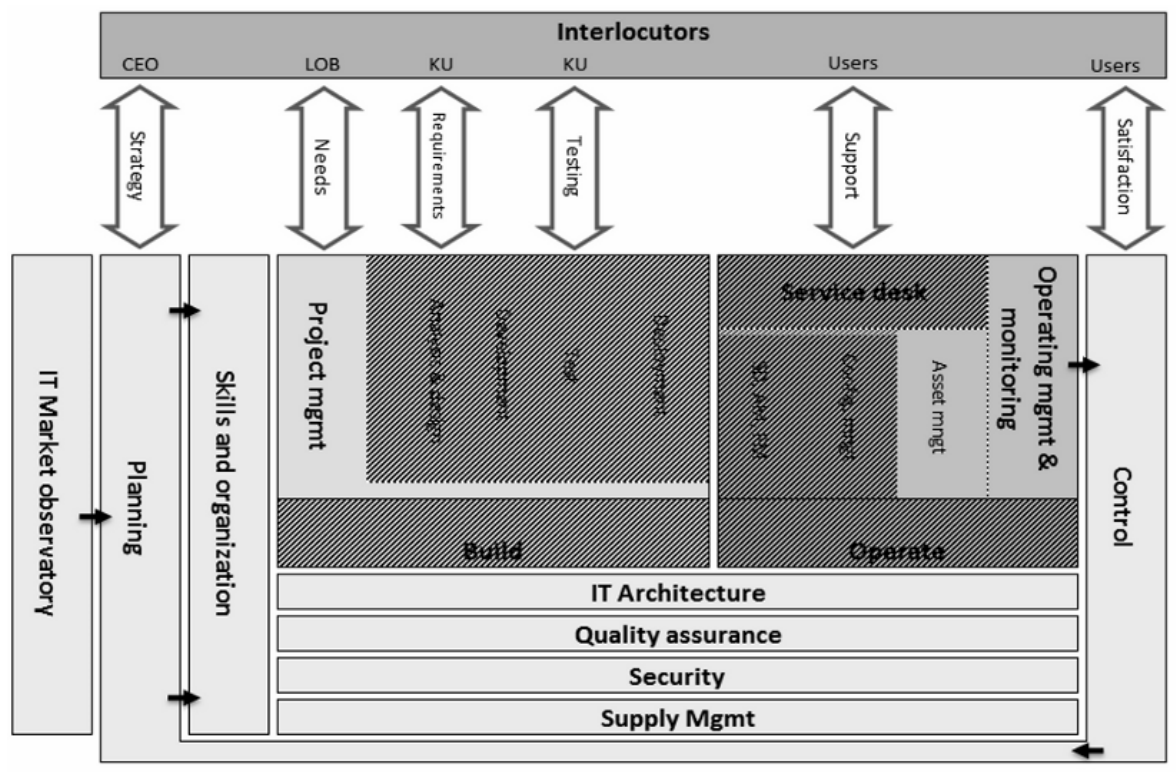

Figure 2 The model with a typical case of IT outsourcing. 


\section{IS function personnel's skills and training needs}

Another property of the model under discussion is that it is composed by sets of homogeneous activities, so each of them requires homogeneous skills too. That is why such a model, besides representing a framework for organizing the IS function, is also useful to build a map of skill requirements.

Even though going into each area of the model thoroughly is beyond the aim of these pages, it is important to underline that IS personnel should have competences both in technical and managerial/financial subjects.

\subsection{Technical skills}

Technical skills are not only referred to IT but also to the business that IT supports. In fact, the IS function (more than others) regard the rest of the organization as an external customer, so it is not sufficient that IS personnel know how to implement solutions, they must also be able to analyze problems, that means to understand customers business requirements.

Sometimes these competences are not to be possessed together (for instance this is true for software developers); other times, for finding the best solutions that fulfill the requirements of the organization it is essential to know jointly both the IT and the subject of the business.

Personnel working in the area called Project management are an example of this: they are just like account managers who receive requirements from their customers (or better: who suggest them new strategic opportunities that IT offers), who find the suitable IT solution and, afterwards, who supervise the implementation of the whole project.

Even in organizations that have recourse of outsourcing (but want to keep the control of the information system and of the IT strategy) IS personnel must have both the kinds of skill. This is particularly evident looking at the Figure 2.

\subsection{Managerial and financial skills}

The more organizations are large and IT spending weigh upon the budget the more IS function needs managerial and financial skills.

Actually, the return of IT investments is one of the most controversial problem in these years.

Evaluating benefits produced by IT is very difficult because they manifest themselves in long period and because they cannot directly be recorded; moreover investing in IT is sometimes an unavoidable choice to remain competitive in comparison with rivals. So, when results of IT spending do not come up to 
expectations, it is not so clear if it happened for wrong evaluations in choosing investments or, rather, for disproportionate expectations.

In any case, this problem implies that IS function needs personnel able to run economic and financial aspects of IT management, at least with regard to activities of programming and management control, cost-benefit analysis within feasibility studies and supply management.

In fact, if these activities were done out of IS function, the consistency between the choices taken for technical reasons and the choices taken for financial reasons could not be assured. For example, in the event of reduction in expendable founds, it would be hoped that cuts in IT spending were decided within IS function.

With particular regard to public administrations, the problem in discussion is even greater. First of all, because the return of investments in literal sense does not exist for public administrations; so benefits deriving from IT are necessarily intangible. Secondly, because supply management is usually subjected to precise rules and regulations, especially concerning suppliers selection; so, in addition to drawing up and managing contracts, it is necessary to draw up calls for bids really assuring the best trade-off between quality and price.

Finally, on the subject of managerial skills, it is enough to say that today IS personnel must knows topics like project management, team working, communication, etc.

\section{The experience of MEF-RGS}

In 2006, a re-training program for IS personnel of the Department for National General Accounting (RGS) of the Italian Ministry of Economy and Finance (MEF) started.

The aim of this program, that is still in progress, is not to improve the activities that IS personnel are already doing, but to develop skills really required to make effective the IS function work. For this why, it cannot be only based on the current IS function organization; on the contrary, the very organization need to be revised. So a model like the one represented in Figure 2 has been used as a reference.

Actually, when the training program started a revising of the IS function was already being carried out, so some skill gaps came out. Nevertheless, by building an abstract model like the one described above, a systematic vision of the matter has been enabled.

Synthetically, the aims of the training program in discussion is making IS personnel able:

- to analyze customers' problems and to understand which IT solutions can be suitable

\footnotetext{
${ }^{2}$ Customers of RGS IS function are mainly internal customers.
} 
- to identify which among new technologies can be useful to improve customers' activities and, in that event, suggest them to customers;

- to deal competently with IT suppliers;

- to oversee all the different stages of IT projects (IT development is outsourced);

- to carry out a full control over the IS operational management (that is outsourced).

After fixing targets, a market research was carried out to select an appropriate system of training.

Finally, the system called European Certification of Informatics Professionals (EUCIP) was chosen, an independent framework of certifications consisting of two degrees: the Core level, that makes a survey of IT and enterprise information systems, and the Elective level, structured in different specialized profiles ${ }^{3}$.

Such a system of certifications has seemed to be suitable to the aim for mainly three reasons:

- being independent of specific IT producers;

- because the syllabus of the Core level gives a synthetic but complete survey of information systems, so that people attending the training program can formalize their knowledge and fill up their gaps; moreover, this help to have a basic IT culture common to all IS personnel;

- because the different professional profiles of the Elective level cover a large part of the competence objective of the training program.

At this point, the training program has started.

In the first stage, concluded in 2007, a group of personnel has obtained the Core level certification, some of them with marks good enough to be qualified for teaching.

In following stages - just starting - some of those personnel will attend different courses to obtain the Elective level certifications (prevalently, as business analyst and IS project manager). At the same time, other personnel will attend new courses for the Core level certification, where the first personnel, that obtained the qualification, will be the teachers.

\section{Conclusions}

EUCIP Core level Syllabus is made up of three modules: Plan, Build and Operate, so each candidate must pass three exams to obtain the certification.

In the experience of RGS-MEF the results of these exams have shown that most of competence gaps regarded the Plan module. This comes up to expectations and confirms that subjects like IT alignment to business strategy,

\footnotetext{
${ }^{3}$ More information are available on http://www.eucip.com.
} 
specific instruments for enterprise information systems, IT spending, project management, etc. are not well known by personnel of IS function.

Of course, this is a serious problem for people that every day, on the one hand, deal with suppliers who sell new technologies like enterprise resource planning, data warehouse, business intelligence systems, etc., and, on the other hand, have to fulfill more and more exigent customer's requirements. So that such a training program, including basic knowledge, is proving to be really useful.

Furthermore, an organization based on a model like the one discussed in these pages seems to be suitable to make the IS function really effective and aligned to the business.

\section{References}

Agarwal R., Sambamurthy V.: Principles and models for organizing the IT function. In MIS Quarterly Executive Vol. 1 No. 1 /March 2002.

Camussone, P.F.: Il sistema informativo aziendale, ETASLIBRI, 1998.

Camussone, P.F.: Informatica organizzazione e strategie, McGraw-Hill, 2000.

Hoffer, J.A., Prescott, M.b., McFadden, F.R. and Morabito, V.: Management delle informazioni aziendali, Pearson Education, 2005.

IT Governance Institute: COBIT Mapping: Overview of International IT Guidance, 2nd Edition. Available on http://www.itgi.org.

McFarlan, F.W.: Information technology changes the way you compete, Harward Business Review, May-June 1984.

Mintzberg, H.: Structure in five. Design effective organization, Prentice Hall, 1983.

Porter, M.E., and Millar,P.E.: How information gives you competitive advantage, Harvard Business Review, July 1985.

Rudd, C. and Hodgkiss, G.: An introductory overview of ITIL, Alison Cartlidge Xansa, 2004

Sciarelli, S.: Fondamenti di economia e gestione delle imprese, CEDAM, 2004.

Tagliavini, M., Ravarini, A. and Sciuto, D.: Sistemi per la gestione dell'informazione, Apogeo, 2003. 